\title{
A Bibliometric Analysis of Optic Coherence Tomography Studies in Multiple Sclerosis
}

\author{
Nedim Ongun, Cagdas Erdogan and Eylem Degirmenci* \\ Pamukkale University, School of Medicine, Department of Neurology, Denizli, Turkey
}

\begin{abstract}
Objective: Optical coherence tomography (OCT) is a non-invasive, non-contact diagnostic tool that provides high-resolution cross-sectional images of the retina that has been used for ten years in multiple sclerosis (MS) related optic neuropathies. The objective of this study is to determine the scientific output in use of OCT in multiple sclerosis between 1982 and 2012 using ISI Web of Knowledge.
\end{abstract}

Methods: The ISI Web of Knowledge was searched for articles on OCT published between 1982 and February 2012 using appropriate terms. Articles were characterized each year by publication type.

Results: Search yielded 154 publications after the search for keywords "optical coherence tomography and multiple sclerosis and 167 publications after the search for the keywords "optical coherence tomography and optic neuritis". After eliminating the conflicting publications total 193 publications were analyzed. A cubic increase in the number of publications over time was observed.

Conclusions: The number of scientific publications in the field of OCT in MS has increased significantly over the past years. The United States, England and Spain have dominated the field of OCT in MS.

Keywords: Optical coherence tomography; Multiple sclerosis; Optic neuritis; Bibliometric analysis

\section{Introduction}

Optical coherence tomography (OCT) is a non-invasive, noncontact diagnostic tool that provides high-resolution cross-sectional images of the retina [1]. The first study to investigate the role of OCT technology in the evaluation of MS patients was reported in the end of 1990 s and after than many studies were performed the use of OCT in MS [2-5]. Most of these papers provide the use of OCT in patients with MS by means of some clinical predictors and/or follow-up assessment method of neurodegeneration, however there opposite reports too [69].

The objective of this study was to provide a global view of the OCT studies in MS. With this aim, we analyzed various parameters of the OCT literature published in journals indexed in the Institute for Scientific Information (ISI) Web of Knowledge database, including the number of publications, type of the publication, countries, top-cited articles and authors, subject of the studies, main results of the studies, publication language, specific journals and funding.

\section{Materials and Methods}

We searched the ISI Web of Knowledge database (1982-2012) using the keywords "optical coherence tomography and multiple sclerosis" or "optical coherence tomography and optic neuritis (ON)". All of the publications were analyzed by the help of abstracts in the ISI Web of Knowledge database and conflicting publications were discreted. We analyzed the number of publications, distribution of the publications by year, publication types (article, letter, proceeding, abstract, review and other), language of the publications, number of publications per journal, publication output by country. In addition subject and main results of the studies were also recorded. We also generated a list of the top 10 OCT-MS related articles based on the citation numbers.

SPSS software (version 15.0; SPSS Inc., Chicago, IL, USA) was used for descriptive statistical analyses. P-values $<0.05$ were considered significant. Regression analysis was used to determine the association between year of publication and the number of publication.

\section{Results}

The ISI Web of Knowledge database search yielded 154 publications after the search for keywords "optical coherence tomography and multiple sclerosis" and 167 publications after the search for the keywords "optical coherence tomography and optic neuritis". After eliminating the conflicting publications total 193 publications were analyzed. All of the abstracts were investigated and 112 publications were found about MS-related optic neuropathies and multiple sclerosis. The animal studies were consisting of $1.8 \%$ of the publications while percentage of studies with definite MS patients was $49.1 \%$ and percentage of studies with MS-related isolated ON patients was $30.4 \%$. The percentage of the patients publications in which the patient group was not determined (Neither definite MS nor MS-related isolated ON patients) was $18.8 \%$. As shown in Table 1, the publication type most frequently used was the article, which constituted $73.2 \%$ of the total publications (82 articles), followed by meeting abstract $(19 ; 17 \%)$, review $(8 ; 7.1 \%)$, editorial material $(2 ; 1.8 \%$ and letter $(1 ; 0.9 \%)$. The year of first publication about use of OCT in MS was 1999, but after 1999 there was no publication until 2004. Table 1 shows the number of publications and types per year between 2004 and 2011. There was a statistically significant cubic increase over time in the total number

*Corresponding author: Dr Eylem Degirmenci, Pamukkale Universities Tip Fakultesi, Noroloji AD, 20070, Kinikli-Denizli, Turkey, Tel: +90258 4440728-5677; Fax: +902582131034; E-mail: eylemteke@yahoo.com

Received December 10, 2013; Accepted January 29, 2014; Published February 09,2014

Citation: Ongun N, Erdogan C, Degirmenci E (2014) A Bibliometric Analysis of Optic Coherence Tomography Studies in Multiple Sclerosis. J Neurol Neurophysiol S12: 007. doi:10.4172/2155-9562.S12-007

Copyright: $\odot 2014$ Ongun N, et al. This is an open-access article distributed under the terms of the Creative Commons Attribution License, which permits unrestricted use, distribution, and reproduction in any medium, provided the original author and source are credited. 


\begin{tabular}{|c|c|c|c|c|c|c|}
\hline Year & Total (n) & Article & Review & $\begin{array}{c}\text { Meeting } \\
\text { abstract }\end{array}$ & $\begin{array}{c}\text { Editorial } \\
\text { material }\end{array}$ & Letter \\
\hline $\mathbf{1 9 9 9}$ & 1 & 1 & 0 & 0 & 0 & 0 \\
\hline $\mathbf{2 0 0 0 - 2 0 0 3}$ & 0 & 0 & 0 & 0 & 0 & 0 \\
\hline $\mathbf{2 0 0 4}$ & 3 & 0 & 0 & 3 & 0 & 0 \\
\hline $\mathbf{2 0 0 5}$ & 4 & 1 & 0 & 3 & 0 & 0 \\
\hline $\mathbf{2 0 0 6}$ & 5 & 3 & 0 & 1 & 1 & 0 \\
\hline $\mathbf{2 0 0 7}$ & 13 & 6 & 2 & 4 & 0 & 1 \\
\hline $\mathbf{2 0 0 8}$ & 14 & 9 & 0 & 5 & 0 & 0 \\
\hline $\mathbf{2 0 0 9}$ & 13 & 12 & 0 & 1 & 0 & 0 \\
\hline $\mathbf{2 0 1 0}$ & 27 & 22 & 3 & 1 & 1 & 0 \\
\hline $\mathbf{2 0 1 1}$ & 30 & 27 & 2 & 1 & 0 & 0 \\
\hline
\end{tabular}

Table 1: Number of publications and types per year between 2004 and 2011.

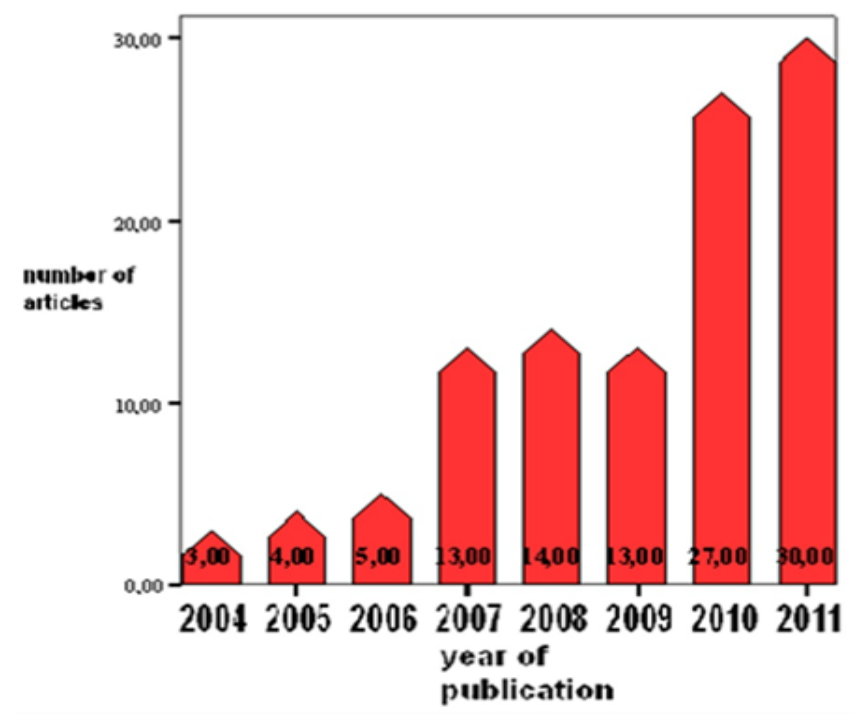

Figure 1: Total number of publications on use of OCT in MS per year of publication (1982-2011).

of publications in the medical literature $(\mathrm{R} 2=94.1 \%, \mathrm{P}<0.0001)$ (Figure 1). Reported funding according to ISI Web of Knowledge database was found $40.2 \%$ of the articles.

We found that publications about the use of OCT in MS were published in 47 different journals. Table 2 shows the list of journal names in which more than two publications were found about use of OCT in MS.

We found that publications about the use of OCT in MS are from total 20 countries (USA, England, Spain, Canada, Multicenter studies from Europe, Germany, Denmark, Australia, Austria, France, Turkey, Italy, Brazil, Hungary, Greece, Holland, China, and Poland). Most of the publications were from U.S.A. and Spain and England are the two other countries following U.S.A. The mean number of citations per publication was 13.2 (range $0-155$ ). Most cited 10 publications with publication title, year and journal name are shown in Table 3. Ninety-four percent of the publications were in the English language (108; 96.4\%). The non-English publications were in German $(2 ; 1.8 \%)$, French $(1 ; 0.9 \%)$, and unspecified $(1 ; 0.9 \%)$.

In this study main results of the publications were also analyzed and results were classified as positive, negative and undetermined results for benefice of OCT in MS. According to our results $68.8 \%$ of the publications had given positive results, $6.3 \%$ of the publications had given negative results but $25.0 \%$ of the publications' results could not be determined. In addition main subjects of the publications were also analyzed in our study. Table 4 summarizes the main subjects of the publications.

\section{Discussion}

Over the last 10 years, the number of publications about use of OCT in MS has gradually increased. The United States ranked first among countries in the overall number of publications. However the number of the publications from some European countries like Spain and England should not be underestimated. Compared with American neurologist and ophthalmologist Europeans are also likely to use OCT as a research topic in MS.

Eighty percent of MS patients present with an acute clinical episode affecting one or several neurological sites, which is known as the clinically isolated syndrome (CIS) [2]. ON is the best studied CIS, and represents the first clinical manifestation of MS in approximately $20 \%$ of cases. In addition to being the clinical inception for many, an additional $30 \%$ to $70 \%$ of patients develop ON during the course of their disease, making the anterior visual pathway a frequent target in MS [2]. OCT has the potential to provide a reliable means of capturing axonal deficits, which can be paired to tests of visual function to provide a structural-functional paradigm of brain injury. In this respect, the eye provides a unique view into the effects of central nervous system inflammation, which may enhance the understanding of disease mechanisms that contribute to neurological disability and pathophysiological mechanisms of neurodegeneration in MS.

The earliest application of OCT technology to the study of MS was reported by Parisi et al. in 1999 [10]. OCT is a promising new tool for evaluating atrophy in patients with $\mathrm{ON}$ and $\mathrm{MS}^{5}$ and this bibliometric study shows that $49.1 \%$ of the all publications were performed on patients with definite MS and the percentage of publications that were performed on patients with MS-related isolated ON was 30.4\%. Most of the studies and the reviews in the literature give positive results about the use of OCT in MS [1-5], however we found that $6.3 \%$ of the all publications had given negative results about the utility of OCT in MS patients.

Although the majority of the publications were published in MS specific journals, our results showed that most cited article about use of OCT in MS were published in neurology and ophthalmology journals rather than MS specific journals and with this result it may be concluded that the new research topic OCT is also in the area of interest of the neurologist and/or neuro-ophthalmologists.

\begin{tabular}{|c|c|}
\hline Journal name & Number of publications \\
\hline Multiple Sclerosis & 12 \\
\hline Neurology & 11 \\
\hline Investigative Ophthalmology and Visual Science & 10 \\
\hline Annals of Neurology & 6 \\
\hline Multiple Sclerosis Journal & 6 \\
\hline Journal of Neuroophthalmology & 5 \\
\hline JONS & 4 \\
\hline European Journal of Ophthalmology & 3 \\
\hline European Journal of Neurology & 3 \\
\hline Brain & 3 \\
\hline Journal of Neurology & 3 \\
\hline Achieves of Neurology & 3 \\
\hline
\end{tabular}

Table 2: Names of the journals in with more than two publication of OCT in MS and number of the publications. 
Citation: Ongun N, Erdogan C, Degirmenci E (2014) A Bibliometric Analysis of Optic Coherence Tomography Studies in Multiple Sclerosis. J Neurol Neurophysiol S12: 007. doi:10.4172/2155-9562.S12-007

Page 3 of 3

\begin{tabular}{|c|c|c|c|c|}
\hline Author & Journal & Title & Year & Times cited \\
\hline Trip et al. & Annals of neurology & Retinal nerve fiber layer axonal loss and visual dysfunction in optic neuritis. & 2005 & 155 \\
\hline Fisher et al. & Ophthalmology & Relation of visual function to retinal nerve fiber layer thickness in multiple sclerosis. & 2006 & 152 \\
\hline Costello et al. & Annals of neurology & Quantifying tonal loss after optic neuritis with optical coherence tomography. & 2006 & 130 \\
\hline Parisi et al. & $\begin{array}{c}\text { Investigative ophthalmology and } \\
\text { visual science }\end{array}$ & $\begin{array}{c}\text { Correlation between morphological and functional retinal impairment in multiple sclerosis } \\
\text { patients. }\end{array}$ & 1999 & 125 \\
\hline Trip et al. & Neuroimage & $\begin{array}{l}\text { Optic nerve atrophy and retinal nerve fibre layer thinning following optic neuritis: } \\
\text { Evidence that axonal loss is a substrate of MRI-detected atrophy. }\end{array}$ & 2006 & 77 \\
\hline Sepulcre et al. & Neurology & Diagnostic accuracy of retinal abnormalities in predicting disease activity in MS. & 2007 & 75 \\
\hline Pulicken et al. & Neurology & Optical coherence tomography and disease subtype in multiple sclerosis. & 2007 & 73 \\
\hline Henderson et al. & Brain & $\begin{array}{l}\text { An investigation of the retinal nerve fibre layer in progressive multiple sclerosis using } \\
\text { optical coherence tomography. }\end{array}$ & 2008 & 51 \\
\hline Zaveri et al. & Achieves of neurology & $\begin{array}{l}\text { Retinal imaging by laser polarimetry and optical coherence tomography evidence of } \\
\text { axonal degeneration in multiple sclerosis. }\end{array}$ & 2008 & 39 \\
\hline Noval et al. & $\begin{array}{l}\text { Acta ophthalmologica } \\
\text { scandinavica }\end{array}$ & Optical coherence tomography versus automated perimetry for follow-up of optic neuritis. & 2006 & 34 \\
\hline
\end{tabular}

Table 3: Most cited 10 publications about use of OCT in MS and MS-related ON.

\section{Subject of the publications}

OCT - Clinical and functional vision comparisons

OCT - Clinical and functional vision and/or visual evoked potential and/or laser polarimerty comparisons

OCT - Clinical and functional vision and MRI (conventional and nonconventional) comparisons

OCT - Clinical and functional vision and automated perimetry comparisons

OCT - technique results

OCT- Clinical and functional vision and retinal vessel analyses comparisons

OCT - Clinical and functional vision and retinal tomography comparisons

OCT - Clinical and functional vision and retinal periphlebitis comparisons

Percentage

$28.6 \%$

20.5

$16.1 \%$

$5.4 \%$

$2.7 \%$

$0.9 \%$

$0.9 \%$

$0.9 \%$

Table 4: Main subjects of the publications.

Main subjects of the publications were compromising comparisons of clinical parameters with electrophysiological tests, conventional and non-conventional MRI techniques and other ophthalmological tests (quantitative ophthalmoscopes). OCT may also be invaluable for evaluating the effects of therapies on patients with MS but according to our results there is not any definite data about the results of MS therapies on OCT parameters. It is possible that MS could be used as a model disease to study degeneration and regeneration of the central nervous system $[11,12]$ and OCT is found beneficial to show progressive neuroaxonal injury in MS in most of the publications. At this point of view, we estimate that publications of OCT in both MS and other neurodegenerative diseases would gradually increase in the forthcoming years. The incorporation of OCT into the study of neurodegenerative disorders will provide new insights into a more global role for this technology in neurologic disease.

OCT can be used in the ON to capture structural changes in the anterior visual pathway, which will provide unique insights regarding pathogenic mechanisms of CNS injury and, in turn, to develop more effective therapeutic strategies for MS patients. As the data from OCT studies continue to mount, there is evidence to support the feasibility of the ON system model in clinical research and potentially, to establish a role for OCT in the diagnosis and treatment of MS patients.

In conclusion, this study represents the first bibliometric assessment of research of OCT in MS literature. Interest in use of OCT in MS and MS-related ON as a valuable clinical tool continues to grow.

\section{References}

1. Miller DH, Altmann DR, Chard DT (2012) Advances in imaging to support the development of novel therapies for multiple sclerosis. Clin Pharmacol Ther 91 621-634
2. Costello FE, Klistorner A, Kardon R (2011) Optical coherence tomography in the diagnosis and management of optic neuritis and multiple sclerosis. Ophthalmic Surg Lasers Imaging. 42: 8-40.

3. Galetta KM, Calabresi PA, Frohman EM, Balcer LJ (2011) Optical coherence tomography (OCT): imaging the visual pathway as a model for neurodegeneration. Neurotherapeutics 8: 117-132.

4. Petzold A, de Boer JF, Schippling S, Vermersch P, Kardon R, et al. (2010) Optical coherence tomography in multiple sclerosis: a systematic review and meta-analysis. Lancet Neurol 9: 921-932.

5. Lamirel C, Newman N, Biousse V (2009) The use of optical coherence tomography in neurology. Rev Neurol Dis 6: E105-120.

6. Kallenbach K, Sander B, Tsakiri A, Wanscher B, Fuglø D, et al. (2011) Neither retinal nor brain atrophy can be shown in patients with isolated unilateral optic neuritis at the time of presentation. Mult Scler 17: 89-95.

7. Serbecic N, Aboul-Enein F, Beutelspacher SC, Graf M, Kircher K, et al. (2010) Heterogeneous pattern of retinal nerve fiber layer in multiple sclerosis. High resolution optical coherence tomography: potential and limitations. PLoS One 5: e13877.

8. Outteryck O, Zephir H, Defoort S, Bouyon M, Debruyne P, et al. (2009) Optical coherence tomography in clinically isolated syndrome: no evidence of subclinical retinal axonal loss. Arch Neurol 66: 1373-1377.

9. Naismith RT, Tutlam NT, Xu J, Shepherd JB, Klawiter EC, et al. (2009) Optical coherence tomography is less sensitive than visual evoked potentials in optic neuritis. Neurology 73: 46-52.

10. Parisi V, Manni G, Spadaro M, Colacino G, Restuccia R, et al. (1999) Correlation between morphological and functional retinal impairment in multiple sclerosis patients. Invest Ophthalmol Vis Sci 40: 2520-2527.

11. Frohman EM, Fujimoto JG, Frohman TC, Calabresi PA, Cutter G, et al. (2008) Optical coherence tomography: a window into the mechanisms of multiple sclerosis. Nat Clin Pract Neurol 4: 664-675.

12. Fong JS, Rae-Grant A, Huang D (2008) Neurodegeneration and neuroprotective agents in multiple sclerosis. Recent Pat CNS Drug Discov 3: 153-165. 